Research paper

\title{
Synthesis and characterization of a Bio-MOF based on mixed adeninate/ tricarboxylate ligands and zinc ions
}

\author{
Edwin A. Giles-Mazón a , Iván Germán-Ramos ${ }^{\mathrm{a}, \mathrm{b}}$, Fernando Romero-Romero ${ }^{\mathrm{a}, \mathrm{b}}$, Eric Reinheimer ${ }^{\mathrm{e}}$, \\ Rubén A. Toscano ${ }^{c}$, Nazario Lopez ${ }^{\mathrm{d}}$, Carlos E. Barrera-Díaz ${ }^{\mathrm{a}, \mathrm{b}}$, Víctor Varela-Guerrero ${ }^{\mathrm{a}, \mathrm{b}, *}$, \\ María F. Ballesteros-Rivas ${ }^{\mathrm{a}, \mathrm{b}, *}$ \\ ${ }^{a}$ Centro Conjunto de Investigación en Química Sustentable UAEM-UNAM, Mexico

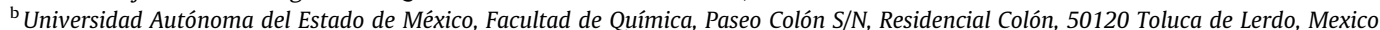 \\ ${ }^{\mathrm{c}}$ Instituto de Química UNAM, Circuito Exterior, C.P. 04510, Ciudad Universitaria, Insurgentes Sur, D.F., Mexico \\ ¿ Centro de Investigaciones Químicas, IICBA, Universidad Autónoma del Estado de Morelos, Av. Universidad 1001, Col. Chamilpa, Cuernavaca, Morelos 62209, Mexico \\ e Rigaku Oxford Diffraction, 9009 New Trails Drive, The Woodlands, TX 77381, United states
}

\section{A R T I C L E I N F O}

Article history:

Received 18 May 2017

Received in revised form 15 September

2017

Accepted 16 September 2017

Available online 20 September 2017

\section{Keywords:}

Metal-organic framework

Adenine coordination modes

Trimesic acid

\begin{abstract}
A B S T R A C T
In this work, we present a new metal organic framework $\mathrm{Zn}_{7}(\mathrm{Ad})_{4}(\mathrm{BTC})_{4}(\mathrm{DMF}) \mathrm{O} \cdot 4 \mathrm{DMA} \cdot 3 \mathrm{DMF} \cdot 4 \mathrm{H}_{2} \mathrm{O}$ which was synthesized under hydrothermal conditions with adenine and trimesic acid (BTC) linkers. The structure was determined by single-crystal (XRD) and the compound was further characterized by Scanning electron microscopy (SEM), infrared spectroscopy (IR), and thermogravimetric analysis. The 3D anionic framework includes adenine present in two-different coordination modes, with dimethylammonium balancing the framework charge.
\end{abstract}

(c) 2017 Elsevier B.V. All rights reserved.

\section{Introduction}

Metal-organic frameworks (MOF) are porous crystalline materials containing metal centers linked by organic units. The organic linkers can be ditopic or polytopic carboxylates as well as similar negatively charged molecules or neutral ligands such as polypyridyl ligands [1-3]. The possibility of using different metal centers in combination with a wide variety of linker ligands provides the opportunity to obtain a plethora of different structures with interesting properties such as gas storage, separations, catalysis, molecular recognition and drug delivery [4-8]. Biomolecules, which include pre-organized recognition moieties, have been used in advanced functional materials due to their high specific binding to small molecules [9-13]. A well probed strategy to include biomolecules in the assembly of crystalline structures with pores and channels is the use of coordination chemistry [7,14-16]. Adenine is an important nitrogen heterocyclic molecule present in nucleic acids and is a versatile molecular building block for the

\footnotetext{
* Corresponding authors at: Universidad Autónoma del Estado de México, Facultad de Química, Paseo Colón S/N, Residencial Colón, 50120 Toluca de Lerdo, Mexico.

E-mail addresses: vvarelag@uaemex.mx (V. Varela-Guerrero), mfballesterosr@uaemex.mx (M.F. Ballesteros-Rivas).
}

construction of porous materials given its rigidity and its possession of several coordination sites, one amino and four nitrogen atoms in the rings, which allow it to show different coordination modes in extended structures (Scheme 1) $[9,17,18]$.

In 2009 Rosi introduced the Bio-MOF as a new family of MOFs incorporating adenine as a secondary building unit (SBU). Based on the strategy that larger angles increase the pore size without the necessity of large linkers, he used metal-adeninate cluster vertices instead of metal carboxylate clusters, and biphenyldicarboxylate as space linkers to synthesize permanently porous materials with the bio MOF-100 having one of the largest pores reported [19]. Another important characteristic is the anionic nature of the framework which can allow cation exchange without loss of crystallinity [20]. These class of materials might have applications in a variety of fields, such as gas separation, molecular adsorption, cation incorporation, and sensing [21,22]. Previous investigations explored the use of carboxylate [23-28] linkers in conjunction with adeninate in several coordination modes [17,29]. The reported bio-MOFs show great variations in porosity, stability, and adsorption of small molecules such as $\mathrm{CO}_{2}$. The structures reveal several coordination modes for adeninate and metal centers when different carboxylate coligands are used [19,20,24,30]. With the intention of expanding the coordination chemistry of adenine 


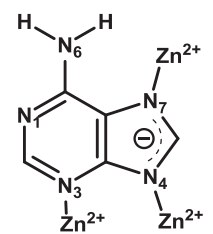

Mode 1

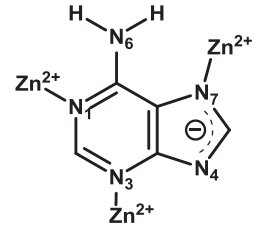

Mode 2

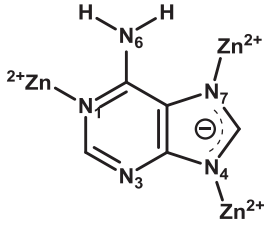

Mode 3
Scheme 1. Representation of the adenine coordination modes observed in BioMOFs showing the labels for the $\mathrm{N}$ binding sites.

in Bio-MOFs in combination with tricarboxylate linkers, herein we report a new anionic metal organic framework based on zinc, adenine and benzene-1,3,5-tricarboxylic acid (BTC).

\section{Materials and methods}

\subsection{General}

All chemicals were purchased from Sigma-Aldrich Chemical Co. and used without further purification.

\subsection{Synthesis of $\mathrm{Zn}_{7}(\mathrm{Ad})_{4}(\mathrm{BTC})_{4}(\mathrm{DMF}) \mathrm{O} \cdot 4 \mathrm{DMA} \cdot 3 \mathrm{DMF} \cdot 4 \mathrm{H}_{2} \mathrm{O}$ (1)}

Adenine $(0.614 \mathrm{mmol})$ was dissolved in $8 \mathrm{~mL}$ of warm DMF while stirring. In another vial, zinc chloride $(0.616 \mathrm{mmol})$ and sodium formate (base used for deprotonating BTC) $(0.614 \mathrm{mmol})$ were added to $4 \mathrm{~mL}$ of DMF and stirred for $10 \mathrm{~min}$, followed by the addition of BTC $(0.618 \mathrm{mmol})$. Finally, nitric acid $(0.2 \mathrm{mmol})$ in $3 \mathrm{~mL}$ of $\mathrm{H}_{2} \mathrm{O}$ was added. The resulting mixture was placed in a sealed autoclave and heated at $130^{\circ} \mathrm{C}$ for $24 \mathrm{~h}$ and then let to slowly cool down to room temperature. Colorless crystals suitable for single-crystal X-ray diffraction were obtained; monoclinic, space group $P_{n} ; a=20.8819(3), b=9.5403(10), c=25.619(3) \AA ;$ $\alpha=90, \beta=101.5828(6), \gamma=90^{\circ} ; \mathrm{V}=4999.99(11) ; \mathrm{Z}=2 . \mathrm{IR}\left(\mathrm{cm}^{-1}\right)$ 3332 (br), 3154 (br), 2795 (w), 1619 (s) 1583 (m), 1469 (w),
1344 (s), 1223 (s), 1149 (w), 1105 (w), 1021 (w), 930 (w), 763 (m), $726(\mathrm{~m}), 574(\mathrm{~s})$. Elemental analysis for (1) C 38.20, H 4.06, N 16.43 Found: C, 38.50, H 3.72, N 15.91.

\subsection{Physical measurements}

Thermogravimetric analyses were carried out in a TA Instruments Hi-Res ${ }^{\mathrm{TM}}$ thermogravimetric analyzer TGA Q5000 (SI). The heating rate was dynamically controlled with instrumental resolution of 5 and Hi-Res sensitivity of 1:00. The atmosphere was created by combining $10 \mathrm{~mL} / \mathrm{min}$ of dry nitrogen balance flow and $25 \mathrm{~mL} / \mathrm{min}$ of dry air oven purge flow. The mass loss profiles of the studied samples were analyzed using the software Universal Analysis $2000 \mathrm{v}$ 4.5A. The IR spectrum of the compound was recorded on an FT-IR in the $4000-400 \mathrm{~cm}^{-1}$ region with a Bruker Tensor 27. Samples in the solid state were measured with the ATR accessory utilizing a diamond crystal and the OPUS software package. The resolution of the spectrometer was $2 \mathrm{~cm}^{-1}$ (Fig. S2). Scanning electron microscopy (SEM, JEOL JSM-6510lV) was also used to analyze the morphology of the crystals.

\subsection{Single crystal structure determination}

Diffraction data were collected with a Bruker-APEX three-circle diffractometer with the use of Mo-K $\alpha$ radiation $(\lambda=0.71073 \AA)$ at $-100^{\circ} \mathrm{C}$. The frames were integrated with the Bruker APEXII software package [31] and a semi-empirical absorption correction was applied using SADABS within the Bruker APEXII software suite. The structure was solved using SHELXT [32] and refined using shelXle, a graphical interface to the SHELX suite of programs [33]. The remaining non-hydrogen atoms were located by alternating cycles of least-squares refinements and difference Fourier maps. All hydrogen atoms were placed in calculated positions.

\subsection{Powder X-ray diffraction}

The phase purity was confirmed using a Rigaku Ultima IV Powder X-ray Diffractometer equipped with $\mathrm{CuK} \alpha$ radiation. Measure-
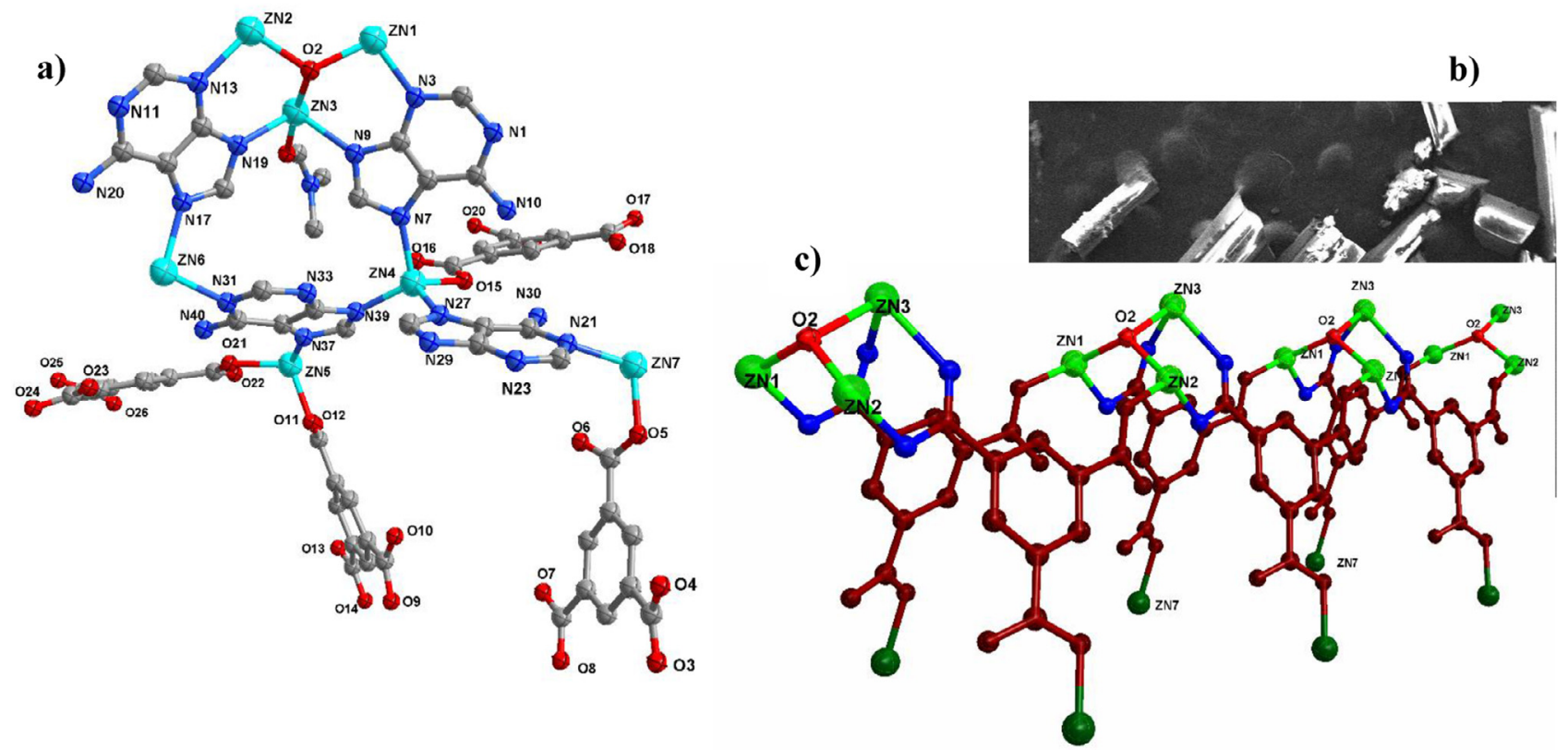

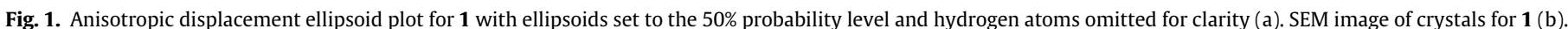

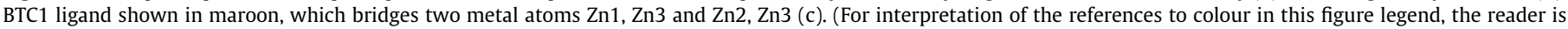
referred to the web version of this article.) 
Table 1

Crystal data for $\mathbf{1}$

\begin{tabular}{ll} 
Formula & $\mathrm{C}_{76} \mathrm{H}_{96} \mathrm{~N}_{28} \mathrm{O}_{33} \mathrm{Zn}_{7}$ \\
Molecular weight & 2387.61 \\
Temp $(\mathrm{K})$ & $100(2)$ \\
Crystal System & Monoclinic \\
Space group & $P n$ \\
$a(\AA)$ & $20.8819(3)$ \\
$b(\AA)$ & $9.54030(1)$ \\
$c(\AA)$ & $25.6196(3)$ \\
$\alpha\left(^{\circ}\right)$ & 90 \\
$\beta\left(^{\circ}\right)$ & $101.5825(6)$ \\
$\gamma\left({ }^{\circ}\right)$ & 90 \\
$V\left(\AA^{3}\right)$ & 4999.99 \\
$Z$ & 2 \\
Color & Colorless \\
$\rho_{\text {calc }}\left(\mathrm{g} / \mathrm{cm}^{3}\right)$ & 1.586 \\
$\mu\left(\mathrm{mm}^{-1}\right)$ & 1.743 \\
$\theta$ range $\left(^{\circ}\right)$ & 1.4 to 27.5 \\
Reflections collected $\left(R_{\text {int }}\right)$ & $69987(0.094)$ \\
Unique reflections & 20302 \\
Parameters/restraints & $1393 / 2382$ \\
$R_{1}{ }^{\mathrm{a}}{ }^{\mathrm{a}} w R_{2}{ }^{\mathrm{b}}[I>2 \sigma(I)]$ & $0.0526,0.1305$ \\
Goodness-of-fit ${ }^{\mathrm{C}}\left(F^{2}\right)$ & 1.007 \\
\hline
\end{tabular}

${ }^{\mathrm{a}} \mathrm{R}=\Sigma|| \mathrm{F}_{\mathrm{o}}|-| \mathrm{F}_{\mathrm{c}}|| / \Sigma\left|\mathrm{F}_{\mathrm{o}}\right|$

b $\left.w \mathrm{R}=\left\{\Sigma\left[w\left(\mathrm{~F}_{\mathrm{o}}^{2}-\mathrm{F}_{\mathrm{c}}^{2}\right)^{2}\right] / \Sigma w\left(\mathrm{~F}_{\mathrm{o}}^{2}\right)^{2}\right]\right\}[24]^{1 / 2}$

c Goodness-of-fit $\left.=\left\{\Sigma w\left(\mathrm{~F}_{\mathrm{o}}^{2}-\mathrm{F}_{\mathrm{c}}^{2}\right)^{2}\right] /(n-p)\right\}^{1 / 2}$, where $n$ is the number of reflections and $p$ is the total number of parameters refined. ments were taken using a step size of $0.02^{\circ}$ and a scan rate of $1^{\circ}$ per minute.

\subsection{The estimated Brunauer-Emmet-Teller (BET) surface}

The adsorption isotherms were recorded using a Micromeritics Accelerated Surface Area and Porosimetry System, ASAP 2020. About $100 \mathrm{mg}$ of the sample were degassed for $1 \mathrm{~h}$ at a pressure below $1.3 \mathrm{~Pa}$ and $473.15 \mathrm{~K}$. After degassing, the sample tube was back filled with nitrogen, disconnected from degas port, immediately sealed with rubber stopper, weighted, covered with the isothermal jacket, transferred to the analysis port, and degassed again in the same conditions. After, the free volume was measured with helium and the sample was degassed again for another $6 \mathrm{~h}$ at room temperature, previous to recording the $\mathrm{N}_{2}$ adsorption isotherm. The $\mathrm{N}_{2}$ adsorption isotherm was performed in a liquid nitrogen bath at a local atmospheric pressure $(\approx 77,981 \mathrm{~Pa})$. After it finished, the sample tube was back filled with nitrogen, disconnected, immediately sealed with rubber stopper, the isothermal jacket removed, and the sample was degassed again for $1 \mathrm{~h}$ at a pressure below $1.3 \mathrm{~Pa}$ and $473.15 \mathrm{~K}$ in the analysis port. The free volume measurement and helium degas procedure were repeated again and $\mathrm{CO}_{2}$ adsorption isotherms at $273.15 \mathrm{~K}$ was recorded. Micromeritics Chiller Dewar option and NESLAB refrigerated bath

a)

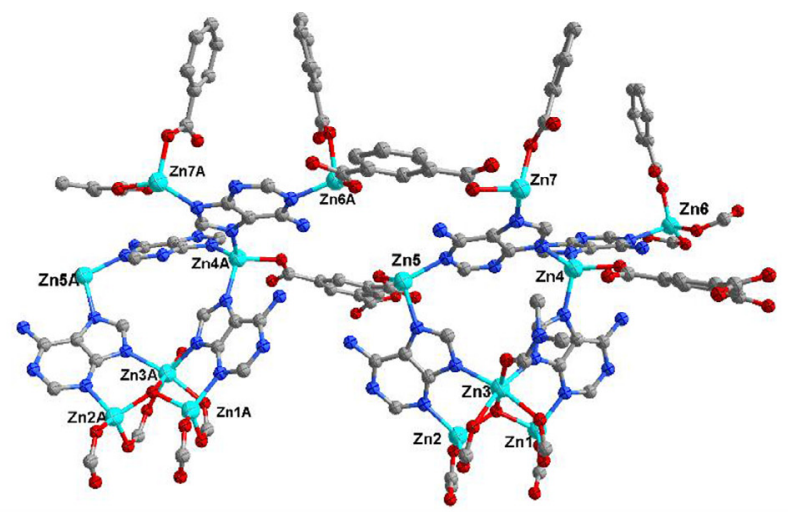

b)

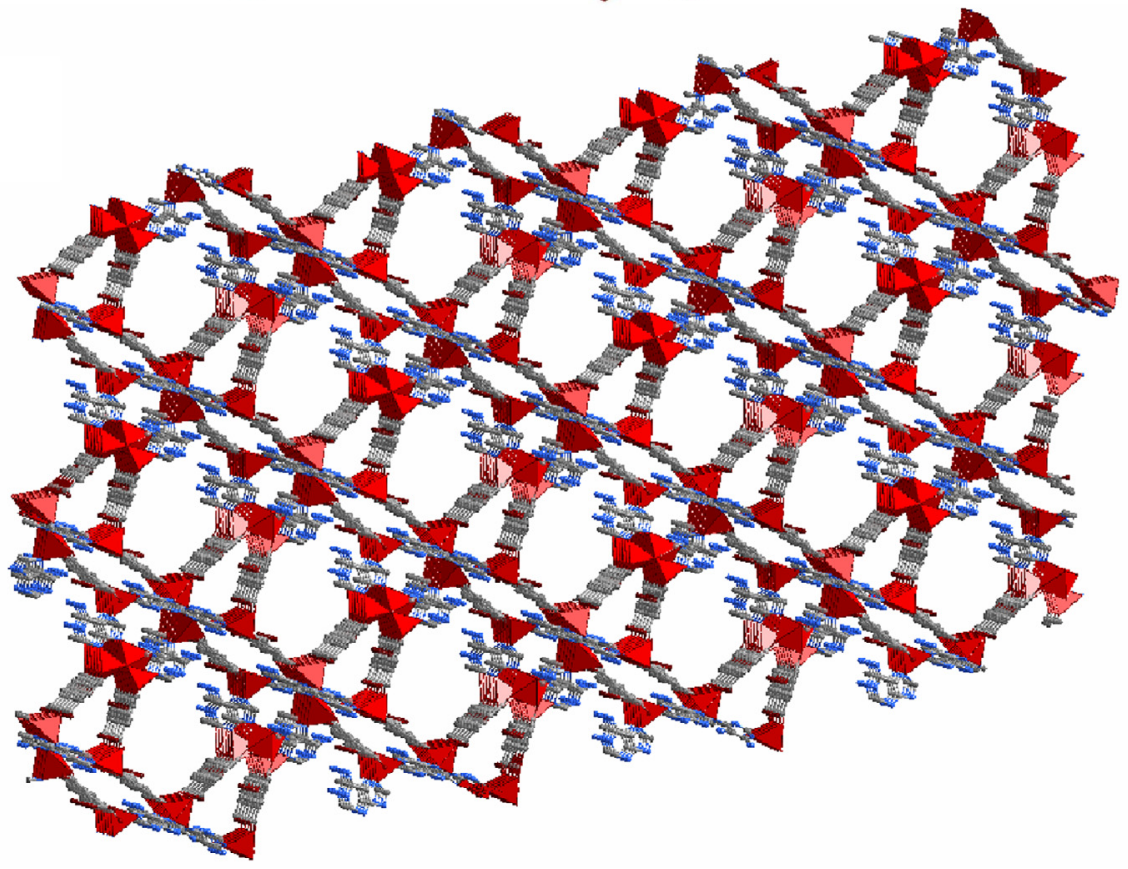

Fig. 2. Secondary building unit of $\mathbf{1}$ (a) and the crystal packing down its $b$-axis (b). 


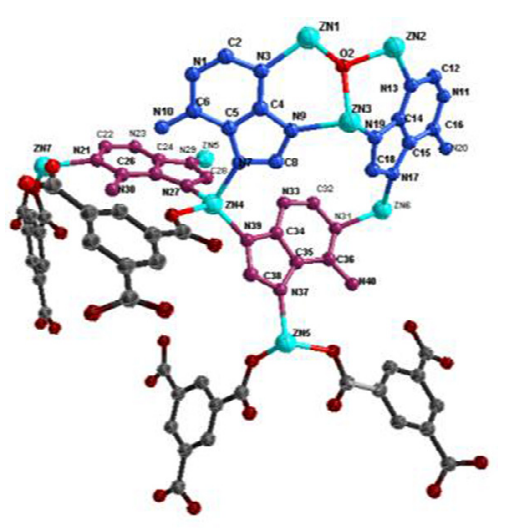

Fig. 3. The different coordination modes of adenine molecules, in blue coordination mode 1 and pink coordination mode 3 . (For interpretation of the references to colour in this figure legend, the reader is referred to the web version of this article.)

model RTE7 were combined to guarantee the cryogenic conditions. All masses were measured using Mettler Toledo XS105DU analytical balance.

\section{Results and discussion}

\subsection{Structure and crystallographic results}

Using hydrothermal synthesis, the colorless compound $\mathrm{Zn}_{7}$ (Ad) $)_{4}$ (BTC $)_{4}$ (DMF)O.4DMA.3DMF.4 $\mathrm{H}_{2} \mathrm{O}$ (1) (Fig. 1) was obtained (Table 1 ). Single crystal $\mathrm{X}$-ray diffraction data revealed that the asymmetric unit of the title compound is composed of seven $\mathrm{Zn}$ (II) and four dimethylammonium cations (DMA), four adeninates, four benzenetricarboxylates (BTC1: C41-C49, O2-07; BTC2: C51-C59, O8-O13; BTC3: C61-C69, O14-019; BTC4: C71-C79, O20-025) and one $\mu_{3}-\mathrm{O}$ dianion, four DMF and four water solvent molecules. All $\mathrm{Zn}$ ions are in tetrahedral environment, with excep- tion of $\mathrm{Zn} 3$ which is in octahedral environment (Table S1). As shown in Scheme 1 , the three $\mu_{3}$ adenine-metal binding modes have been observed in the structure: Ad1 and Ad2 have binding mode 1, while Ad3 and Ad4 have mode 3 (Scheme 1). In addition, all carboxylates of the BTC moieties act as monodentate ligands coordinated to a single metal-atom except for BTC1 which bridge two metal atoms $\mathrm{Zn} 1, \mathrm{Zn} 3$ and $\mathrm{Zn} 2, \mathrm{Zn} 3$ (Fig. 1). None of the BTC moieties are strictly planar, the carboxylate moieties turn out of plane from their corresponding benzene ring planes by torsional angles ranging from $3.6(5)$ to $34.0(4)^{\circ}$. Six of the metal ions display three different slightly distorted tetrahedral coordination spheres: $\mathrm{N}, \mathrm{O}, \mathrm{O}, \mathrm{O}(\mathrm{Zn} 1, \mathrm{Zn} 2, \mathrm{Zn7})$; N,N,O,O (Zn5, Zn6) and N,N,N,O (Zn4) with the nitrogen atoms from the adeninates and the oxygen atoms from the $\mu_{3}-\mathrm{O}^{2-}$ and carboxylates anions, respectively. The remaining $\mathrm{Zn} 3$ displays a distorted N,N,O,O,O,O octahedral coordination mode and includes an oxygen atom contribution from a coordinated DMF solvent molecule.

The Secondary Building Unit (SBU) can be described as a tetranuclear-decorated macrocycle composed of 20 atom ring containing adeninate Ad1 bridging $\mathrm{Zn} 1$ and $\mathrm{Zn} 4$, Ad2 bridging $\mathrm{Zn} 4$ and $\mathrm{Zn} 5$ and Ad3 bridging $\mathrm{Zn} 2$ and $\mathrm{Zn} 5$. To close the cycle, the 01 bridges $\mathrm{Zn} 2$ and $\mathrm{Zn} 1$. The binding of $\mathrm{Zn} 3$ to this ring results in a trinuclear moiety, while a fourth adeninate Ad4 bridges $\mathrm{Zn} 4$ and Zn6 in conjunction with Zn7 form pendant decorations on opposite sides of the macrocyclic plane (Fig. 2a). These SBU's are linked together through the BTC3 and BTC4 organic linkers and are coordinated by the zinc atoms Zn5, Zn6 and Zn7 related by the $(0.5+x,-y, 0.5+z)$ symmetry operation. These interactions appear to be directly responsible for the extension of the structure within the $(-101)$ plane (Fig. 2a), crosslinked by the BTC1 and BTC2 organic linkers to generate a three-dimensional (3D) framework. This connectivity pattern results in channels that run parallel to the crystallographic $b$-axis (Fig. 2b). Propagated by the connectivity outlined above, $\mathbf{1}$ is an anionic framework within which dimethylammonium cations (the product of DMF decomposition) [29], as well as interstitial DMF and water molecules, reside in the channels.

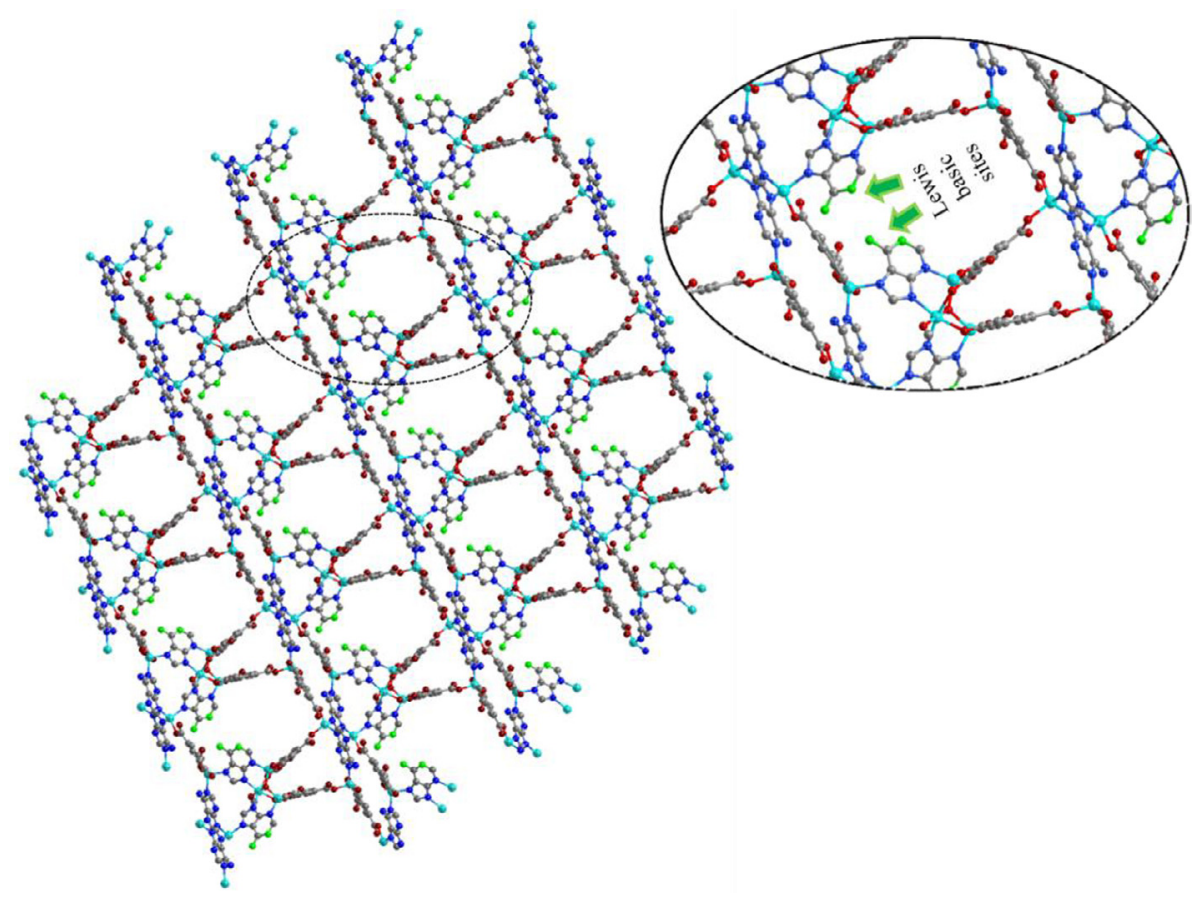

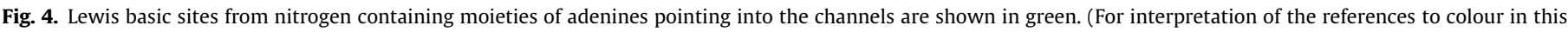
figure legend, the reader is referred to the web version of this article.) 


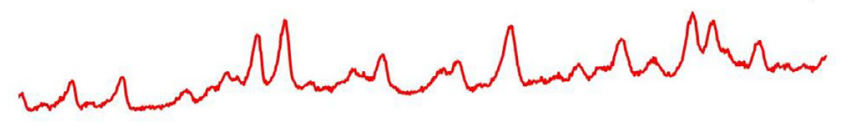

b)
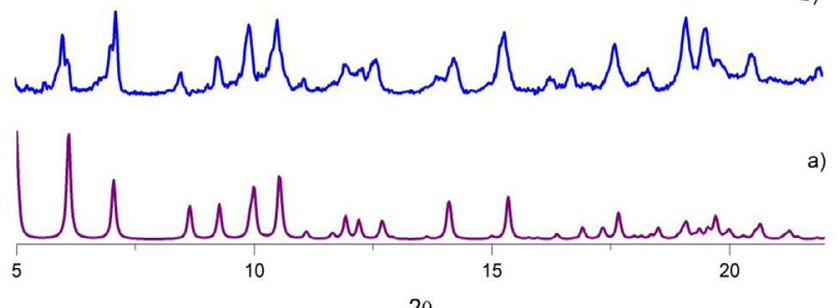

$2 \theta$

Fig. 5. PXRD patterns for $\mathrm{Zn}_{7}(\mathrm{Ad})_{4}(\mathrm{BTC})_{4}(\mathrm{DMF}) \mathrm{O} \cdot 4 \mathrm{DMA} \cdot 3 \mathrm{DMF} \cdot 4 \mathrm{H}_{2} \mathrm{O}$ simulated from the crystal model (a) and the "as-synthesized" bulk material (b) and desolvated compound (c).

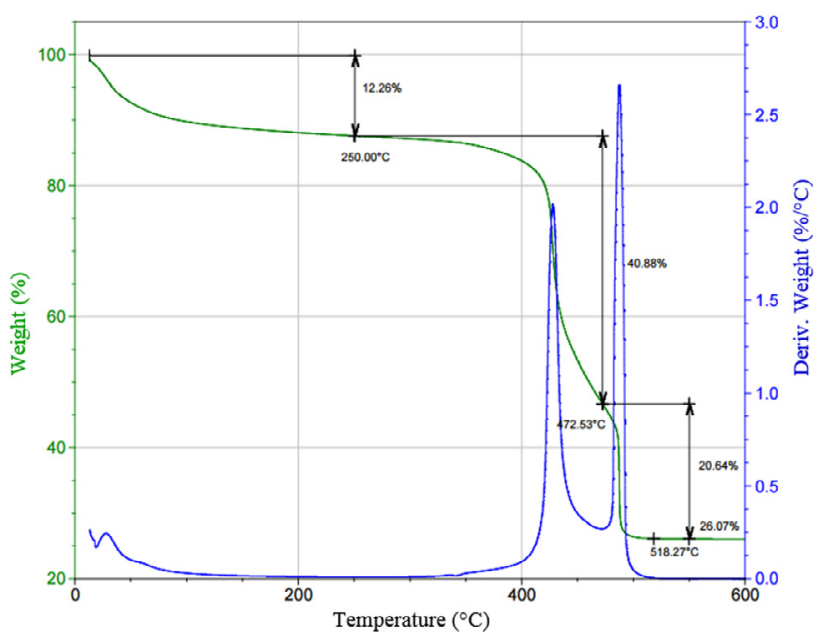

Fig. 6. Thermogravimetric curve of $\mathrm{Zn}_{7}(\mathrm{Ad})_{4}(\mathrm{BTC})_{4}(\mathrm{DMF}) \mathrm{O} \cdot 4 \mathrm{DMA} \cdot 3 \mathrm{DMF} \cdot 4 \mathrm{H}_{2} \mathrm{O}$.

To our knowledge, the Bio-MOFs reported to date show coordination modes 1 and 2 (Scheme 1 ) for adenine. For the previous Bio-Mofs reported, 11, 12, 13 and 14, the adenine presents a coordination mode 1 through N3, N7 and N9 to three metal centers, allowing nitrogen atoms N1 and N6 from the amino group and heterocycle to be uncoordinated. Within Bio-MOF-1 and Bio-MOF-100, the adenine coordinates to four metal centers via a type 1 coordination mode through N3, N7 and N9. Upon close inspection of the present compound, coordination mode 3 is observed in addition to the common coordination mode 1 . The adenine in mode 3 is coordinated to three metal centers through N1, N7 and N9 while simultaneously leaving free N3 and N6 from the amino group and heterocycle (Fig. 3).

In the title compound the two uncoordinated nitrogen atoms from both adenines mode 1 (Ad1:N1, N10; Ad2:N11, N20) are directly pointing to the largest pore (Fig. 4), which could enhance $\mathrm{CO}_{2}$ adsorption. Theoretical studies and experimental reports show that free Lewis basic sites of adenine have higher interaction with $\mathrm{CO}_{2}$ than other nitrogen-containing ligands in MOFs, thus increasing the adsorption properties [34-38]. In addition, Rosi highlighted the advantage of having adenine molecules pointing into the channels in related Bio-MOFs 11-14, which show good $\mathrm{CO}_{2}$ adsorption and selectivity [20].
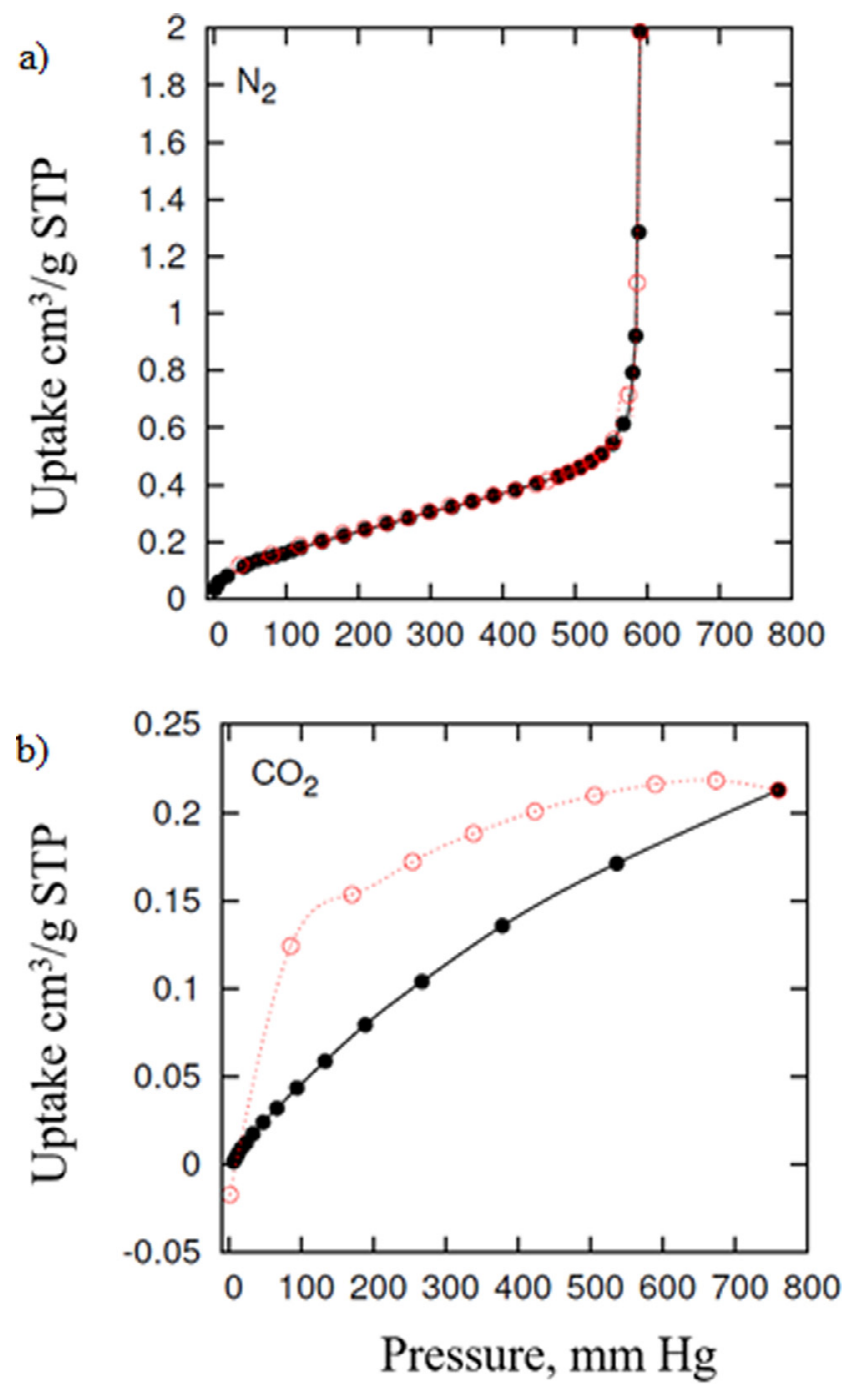

Fig. 7. Nitrogen adsorption isotherms at $77 \mathrm{~K}$ (a); carbon dioxide adsorption isotherms at $273.15 \mathrm{~K}$ of the degasified samples (b). Isotherms adsorption are plotted with black filled circles and desorption by red open circles. (For interpretation of the references to colour in this figure legend, the reader is referred to the web version of this article.)

\subsection{Thermogravimetric analysis}

To assess the thermal stability of $\mathbf{1}$, thermogravimetric analyses (TGA) on single-phase polycrystalline samples of the compound were conducted. The TGA curve (Fig. 6) showed a single loss of $12.26 \%$ suggesting the loss of solvent. Evidence of sample decomposition was observed at $\sim 420^{\circ} \mathrm{C}$.

\subsection{Surface area}

As shown in Fig. 7, the sorption properties of $\mathbf{1}$ were also investigated. From crystallography, the size of the largest pore was determined to be $\sim 15 \AA$ by $10 \AA$ (Fig. S1). At the end of the degassing process the sample lost $11.58 \%$ of its weight, which is in agreement with the weight loss corresponding to the desolvation event in the TGA curve (Fig. 6). However, the nitrogen adsorption isotherm is characteristic of non-porous material (Fig. 7). The surface area estimated from this isotherm was $16.7(2) \mathrm{m}^{2} / \mathrm{g}$ (with $C_{B E T}=20.9$ ), which is characteristic of non-porous material. This suggests that the accessibility of the $\mathrm{N}_{2}$ molecule to the sample porosity is restricted probably by steric effects. $\mathrm{CO}_{2}$ adsorption is 
also low. However, the isotherm shows a hysteresis loop that suggests partial access of the $\mathrm{CO}_{2}$ molecules into the framework. The temperature increase in the adsorption experiment and the smaller kinetic diameter of $\mathrm{CO}_{2}(0.33 \mathrm{~nm})$ molecules than $\mathrm{N}_{2}(0.36 \mathrm{~nm})$ could favored their diffusion into the framework. The hysteresis loop suggest that channels width and kinetic diameter of $\mathrm{CO}_{2}$ molecules are very close. The desorption process at low pressure suggest that DMA molecules remain blocking the gates The framework did not collapse during desolvation process, as evidenced by powder X-ray diffraction data which looks almost identical for desolvated and as-synthesized samples (Fig. 5).

The decreased surface area is attributed to the fact that the four DMA molecules are still inside the pore, this was also observed in BioMOF1, because by conventional activation methods DMA are not removed due to the requirement of charge neutrality of the material. In addition, one-half of two adenine molecules are directly pointing into the pores, diminishing the size of the pore gate, which is much smaller than the porous of $30 \AA$ radius observed in Bio-MOF-1. This could be compared with the isoreticular Bio-MOF-13 and Bio-MOF-14, in which the effect of reduced pore volume as a function of aliphatic chain inclusion within the pores of the bio-MOF was studied. As expected, the surface area decreased with the longest aliphatic chains $\left(412 \mathrm{~m}^{2} \cdot \mathrm{g}^{-1}\right.$, $17 \mathrm{~m}^{2} \cdot \mathrm{g}^{-1}$ respectively); compared to those achieved for bioMOF-11 $\left(1040 \mathrm{~m}^{2} \cdot \mathrm{g}^{-1}\right)$ where aliphatic chains were absent. Despite this, Bio-MOFs 13 and 14 demonstrated good $\mathrm{CO}_{2}$ selectivity, supporting the idea that selectivity can be achieved upon consideration of both functionalization and surface area [20].

\section{Conclusions}

In this work, we report the synthesis of a new bio Metal Organic Framework from a hydrothermal reaction involving divalent zinc, adenine and benzenetricarboxylic acid. The compound $\mathrm{Zn}_{7}(\mathrm{Ad})_{4}(-$ BTC $)_{4}$ (DMF)O-4DMA.3DMF.4 $\mathrm{H}_{2} \mathrm{O}$ exhibits a structure wherein two adeninates point into the biggest pore leaving two uncoordinated nitrogen atoms.

In addition, given the anionic nature of the network, analyses are currently ongoing to evaluate the candidacy of the compound to function as a host for multiple cationic molecules and $\mathrm{CO}_{2}$ adsorption.

\section{Acknowledgements}

The authors thank Facultad de Química UAEMex, Gibran Bautista-Vazquez Q.F.B. Karla Eriseth Reyes Morales, Dr. Diego Martinez-Otero. M. C. Lizbeth Triana-Cruz and M. C. Alejandra Núñez for technical assistance.

\section{Funding}

NL is grateful for financial support from the Secretary of Public Education (SEP-PROMEP grant).

\section{Appendix A. Supplementary data}

Supplementary data associated with this article can be found, in the online version, at http://dx.doi.org/10.1016/j.ica.2017.09.047.

\section{References}

[1] A.G. Slater, A.I. Cooper, Science 348 (2015).

[2] S. Kitagawa, R. Kitaura, S.-I. Noro, Angew. Chem. Int. Ed. 43 (2004) 2334-2375.

[3] T.R. Cook, Y.R. Zheng, P.J. Stang, Chem. Rev. 113 (2013) 734-777.

[4] H. Furukawa, K.E. Cordova, M. O’Keeffe, O.M. Yaghi, Science 341 (2013).

[5] R.J. Kuppler, D.J. Timmons, Q.-R. Fang, J.-R. Li, T.A. Makal, M.D. Young, D. Yuan, D. Zhao, W. Zhuang, H.-C. Zhou, Coord. Chem. Rev. 253 (2009) 3042-3066.

[6] Y.-B. Zhang, H. Furukawa, N. Ko, W. Nie, H.J. Park, S. Okajima, K.E. Cordova, H. Deng, J. Kim, O.M. Yaghi, J. Am. Chem. Soc. 137 (2015) 2641-2650.

[7] H. Li, M. Eddaoudi, M. O'Keeffe, O.M. Yaghi, Nature 402 (1999) 276-279.

[8] P. Horcajada, R. Gref, T. Baati, P.K. Allan, G. Maurin, P. Couvreur, G. Férey, R.E. Morris, C. Serre, Chem. Rev. 112 (2012) 1232-1268.

[9] S. Verma, A.K. Mishra, J. Kumar, Acc. Chem. Res. 43 (2010) 79-91.

[10] B. Lippert, Coord. Chem. Rev. 200-202 (2000) 487-516.

[11] E.-C. Yang, Y.-N. Chan, H. Liu, Z.-C. Wang, X.-J. Zhao, Cryst. Growth Des. 9 (2009) 4933-4944.

[12] J. Thomas-Gipson, G. Beobide, O. Castillo, M. Fröba, F. Hoffmann, A. Luque, S. Pérez-Yáñez, P. Román, Cryst. Growth Des. 14 (2014) 4019-4029.

[13] S. Das, C. Madhavaiah, S. Verma, P.K. Bharadwaj, Inorg. Chim. Acta 358 (2005) 3236-3240.

[14] Y. Lin, C. Kong, L. Chen, RSC Adv. 6 (2016) 32598-32614.

[15] Z. Qiao, N. Wang, J. Jiang, J. Zhou, Chem. Commun. 52 (2016) 974-977.

[16] K. Sumida, D.L. Rogow, J.A. Mason, T.M. McDonald, E.D. Bloch, Z.R. Herm, T.-H. Bae, J.R. Long, Chem. Rev. 112 (2012) 724-781.

[17] I. Burneo, K.C. Stylianou, S. Rodríguez-Hermida, J. Juanhuix, X. Fontrodona, I. Imaz, D. Maspoch, Cryst. Growth Des. 15 (2015) 3182-3189.

[18] E.-C. Yang, H.-K. Zhao, B. Ding, X.-G. Wang, X.-J. Zhao, New J. Chem. 31 (2007) 1887-1890.

[19] J. An, O.K. Farha, J.T. Hupp, E. Pohl, J.I. Yeh, N.L. Rosi, Nat. Commun. 3 (2012) 604.

[20] J. An, S.J. Geib, N.L. Rosi, J. Am. Chem. Soc. 132 (2010) 38-39.

[21] S. Zhang, H. He, F. Sun, N. Zhao, J. Du, Q. Pan, G. Zhu, Inorg. Chem. Commun. 79 (2017) 55-59.

[22] J.A. Bohrman, M.A. Carreon, Chem. Commun. 48 (2012) 5130-5132.

[23] S.R. Sushrutha, R. Hota, S. Natarajan, Eur. J. Inorg. Chem. 2016 (2016) 29622974.

[24] T. Li, D.-L. Chen, J.E. Sullivan, M.T. Kozlowski, J.K. Johnson, N.L. Rosi, Chem. Sci. 4 (2013) 1746-1755.

[25] J. Du, G. Zou, Inorg. Chem. Commun. 69 (2016) 20-23.

[26] H.-R. Fu, J. Zhang, Chem. - A Eur. J. 21 (2015) 5700-5703.

[27] J. An, S.J. Geib, M.-G. Kim, S.Y. Choi, W.T. Lim, J. Porous Mater. 22 (2015) 867875.

[28] H. Cai, M. Li, X.-R. Lin, W. Chen, G.-H. Chen, X.-C. Huang, D. Li, Angew. Chem. Int. Ed. 54 (2015) 10454-10459.

[29] J. An, C.M. Shade, D.A. Chengelis-Czegan, S. Petoud, N.L. Rosi, J. Am. Chem. Soc. 133 (2011) 1220-1223.

[30] J. An, S.J. Geib, N.L. Rosi, J. Am. Chem. Soc. 131 (2009) 8376-8377.

[31] Bruker AXS, Madison, WI, 2013.

[32] G.M. Sheldrick, Acta Crystallogr. Sect. A: Found. Crystallogr. A64 (2008) 112122.

[33] C.B. Hubschle, G.M. Sheldrick, B. Dittrich, J. Appl. Crystallogr. 44 (2011) 1281 1284.

[34] K.D. Vogiatzis, A. Mavrandonakis, W. Klopper, G.E. Froudakis, ChemPhysChem 10 (2009) 374-383.

[35] E.F. da Silva, H.F. Svendsen, Int. J. Greenhouse Gas Control 1 (2007) 151-157.

[36] Y. Chen, J. Jiang, ChemSusChem 3 (2010) 982-988.

[37] K.C. Stylianou, J.E. Warren, S.Y. Chong, J. Rabone, J. Bacsa, D. Bradshaw, M.J. Rosseinsky, Chem. Commun. 47 (2011) 3389-3391.

[38] S. Pérez-Yáñez, G. Beobide, O. Castillo, M. Fischer, F. Hoffmann, M. Fröba, J. Cepeda, A. Luque, Eur. J. Inorg. Chem. 2012 (2012) 5921-5933. 